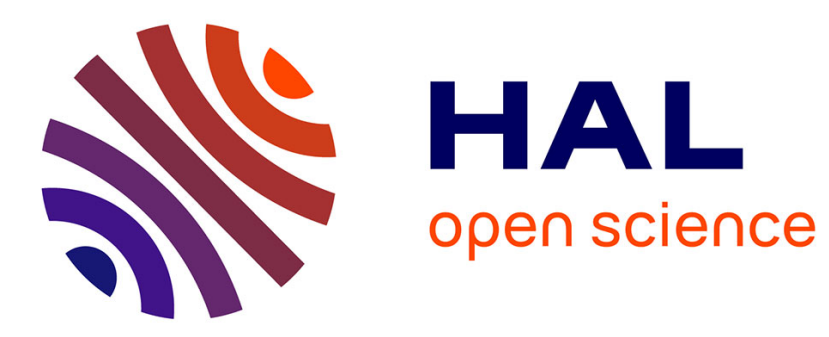

\title{
Infrared spectrum of FeF2
}

J. Giordano, El Alaoui-Bichri, C. Benoit, R. Almairac, A.M. Bon

\section{- To cite this version:}

J. Giordano, El Alaoui-Bichri, C. Benoit, R. Almairac, A.M. Bon. Infrared spectrum of FeF2. Journal de Physique Lettres, 1979, 40 (7), pp.153-156. 10.1051/jphyslet:01979004007015300 . jpa-00231595

\section{HAL Id: jpa-00231595 https://hal.science/jpa-00231595}

Submitted on 1 Jan 1979

HAL is a multi-disciplinary open access archive for the deposit and dissemination of scientific research documents, whether they are published or not. The documents may come from teaching and research institutions in France or abroad, or from public or private research centers.
L'archive ouverte pluridisciplinaire HAL, est destinée au dépôt et à la diffusion de documents scientifiques de niveau recherche, publiés ou non, émanant des établissements d'enseignement et de recherche français ou étrangers, des laboratoires publics ou privés. 


\title{
Infrared spectrum of $\mathrm{FeF}_{2}$
}

\author{
J. Giordano, El Alaoui-Bichri (*), C. Benoit, R. Almairac and A. M. Bon \\ Laboratoire de Physique Moléculaire et Cristalline, Groupe de Dynamique des Phases condensées (**), \\ U.S.T.L., 34060 Montpellier Cedex, France
}

(Reçu le 4 décembre 1978, accepté le 5 février 1979)

\begin{abstract}
Résumé. - Les spectres de réflexion infrarouge à température ambiante sont présentés pour le composé $\mathrm{FeF}_{2}$ de structure rutile. Ils sont analysés par deux méthodes : une méthode classique de réponse en terme d'oscillateurs, et une analyse de Kramers-Kronig. Une faible bande supplémentaire apparaît dans le spectre correspondant à une polarisation parallèle à l'axe. Une interprétation par un processus à deux phonons est proposée. Par contre, la bande supplémentaire mise en évidence par l'analyse de Kramers-Kronig pour la polarisation perpendiculaire à l'axe n'est pas expliquée.

Abstract. - Infrared reflectivity spectra at room temperature are presented for the rutile structure compound $\mathrm{FeF}_{2}$ and analysed by two methods : a classical oscillator response and a Kramers-Kronig analysis. A weak supplementary sideband appears in the spectrum for polarization parallel to the axis. An interpretation by a twophonon process is proposed. The supplementary band revealed by the Kramers-Kronig analysis for polarization perpendicular to the axis is however not explained.
\end{abstract}

Among the four fluoride compounds $\mathrm{MgF}_{2}, \mathrm{MnF}_{2}$, $\mathrm{ZnF}_{2}$ and $\mathrm{FeF}_{2}$, which crystallize with the rutile structure (P $42 / \mathrm{mnm})$; iron fluoride is of particular interest : in addition to the direct magnon-phonon coupling observed by neutron scattering techniques [1] a magnetostriction induced coupling is observed between the para-antiferromagnetic ordering and the first order Raman spectrum of phonons [2]. Contrary to the three other compounds the only infrared optical measurements performed until now on this crystal are a rather incomplete transmission spectrum [3]. A group character analysis shows that this material should present three doubly degenerate infrared active modes $\left(3 \mathrm{E}_{u}\right)$ with polarization perpendicular to the four fold $\mathrm{c}$ axis and one non degenerate mode parallel to the $c$ axis $\left(\mathrm{A}_{2 \mathrm{u}}\right)$.

We report here our measurements on this material at room temperature. A more complete analysis including a model interpretation and temperature effects will be given elsewhere.

1. Experimental. - The single crystal sample of $\mathrm{FeF}_{2}$ provided by Cristal $\mathrm{Tec}$ (Leti-Grenoble) was oriented by X-rays then cut and polished by the usual techniques. Our sample is optically clear and light yellow in colour. A rectangular sample 15 by 10 by

(*) Present address : Faculté des Sciencés, Av. Moulay Cherif, Rabat, Maroc.

(**) Associated with the C.N.R.S., (LA 233).

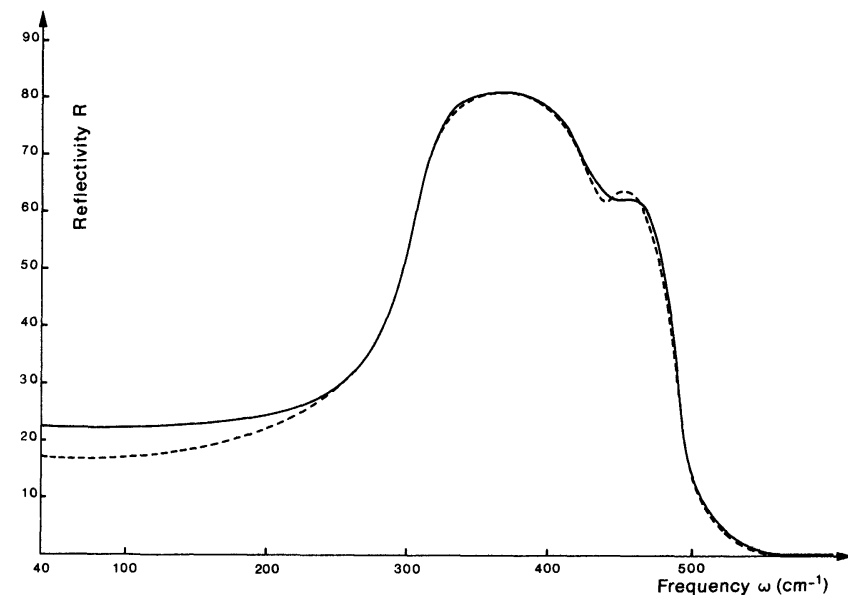

Fig. 1. - Room temperature reflection spectra of $\mathrm{FeF}_{2}$ for a polarization parallel to the axis. The full line is the measured reflectivity whereas the dashed line represents reflectivity calculated by an oscillator model.

$4 \mathrm{~mm}$ was cut with c axis parallel to largest edge.

Room temperature reflection spectra were taken in the range $350-5000 \mathrm{~cm}^{-1}$ with an infrared spectrometer built in our laboratory. The angle of incidence was less than $6^{\circ}$. In the $40-400 \mathrm{~cm}^{-1}$ frequency range we used a Fourier transform spectrometer. The measured reflectivities are shown in figures 1,2 .

2. Discussion. - Two methods have been used for the analysis of the reflectivity spectra : one method 


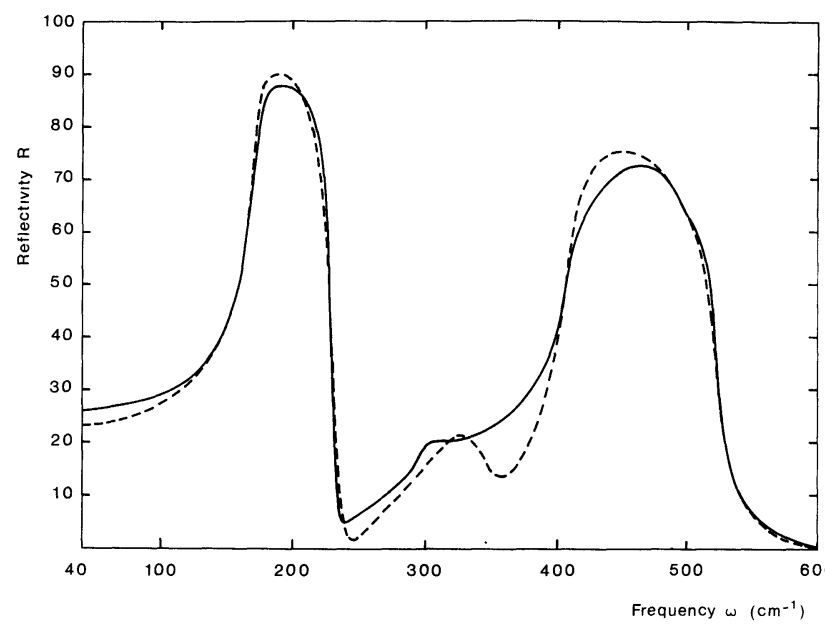

Fig. 2. - Room temperature reflection spectra of $\mathrm{FeF}_{2}$ for a polarization perpendicular to the axis : the definitions of full and dashed lines are as in figure 1 .

using classical oscillator dispersion theory and the other using a Kramers-Kronig analysis.

The first method consists in introducing 3 oscillators for the polarization perpendicular to the $\mathbf{c}$ axis ( $E_{u}$ modes) and one oscillator for the polarization parallel to the axis $\left(A_{2 u}\right.$ mode) (plus one weak modesee later). From this model it is possible to calculate the dielectric constant tensor $\overline{\bar{*}}(\omega)$ and then the reflectivity spectrum for each of the two polarizations. By a fitting procedure, values for the strengths, frequencies and line widths of each oscillator are obtained so that the measured infrared reflectivity is correctly reproduced. The infinite dielectric constant was obtained by extrapolating measurements of the reflection index in the visible region using the Abbe refractometer. The results are shown in figures 1 and 2 . The mode parameters are given in table I. We present, too, the longitudinal mode frequencies obtained with the values of dampings in response function equal to zero (Barker [5]).

The reflectivity is well described for the $\mathrm{A}_{2 u}$ mode but is poorly described in the $200-300 \mathrm{~cm}^{-1}$ region for the polarization perpendicular to the $\mathbf{c}$ axis.

It is evident that the response function of this crystal cannot be simply described by a classical oscillator dispersion model.

To obtain the response function

$$
\overline{\bar{\varepsilon}}(\omega)=\overline{\bar{\varepsilon}}^{\prime}(\omega)+i \overline{\bar{\varepsilon}}^{\prime \prime}(\omega)
$$

we apply a Kramers-Kronig analysis.

The phase shift of the electromagnetic field after reflection is given by [11]

$$
\theta(\omega)=\frac{\omega}{\pi} P \int_{0}^{\infty} \frac{\ln R\left(\omega^{\prime}\right)-\ln R(\omega)}{\omega^{2}-\omega^{\prime 2}} \mathrm{~d} \omega^{\prime}
$$

Table I. - Parameters of the infrared modes at room temperature.

Oscillator dispersion analysis :

$$
\varepsilon(\omega)=\varepsilon_{\infty}+\sum_{j} \frac{\zeta_{j}^{2}}{\omega_{j}^{2}-\omega^{2}-i \omega \Gamma_{j}}
$$

$$
\begin{aligned}
& \text { Polarization } \\
& / / \mathbf{c} \quad \varepsilon_{\infty}=2.275 \\
& \mathbf{A}_{2 \mathrm{u}}\left\{\begin{array}{c}
\zeta_{j}=565 \mathrm{~cm}^{-1} \\
\Gamma_{j}=24 \mathrm{~cm}^{-1} \\
\omega_{\mathrm{t}}=312 \mathrm{~cm}^{-1} \\
\omega_{\mathrm{L}}=490 \mathrm{~cm}^{-1}
\end{array}\right. \\
& \text { Side band }\left\{\begin{array}{c}
\zeta_{j}=50 \mathrm{~cm}^{-1} \\
\Gamma_{j}=26 \mathrm{~cm}^{-1} \\
\omega_{0}=437 \mathrm{~cm}^{-1}
\end{array}\right. \\
& \text { Polarization } \\
& \perp \text { c } \quad \varepsilon_{\infty}=2.285 \\
& \mathrm{E}_{\mathrm{u} 1}\left\{\begin{array}{l}
\zeta_{j}=350.8 \mathrm{~cm}^{-1} \\
\Gamma_{j}=5.45 \mathrm{~cm}^{-1} \\
\omega_{\mathrm{t} 2}=171.5 \mathrm{~cm}^{-1} \\
\omega_{\mathrm{L}}=232 \mathrm{~cm}^{-1} \\
\mathrm{E}_{\mathrm{u} 3}=257.5 \mathrm{~cm}^{-1} \\
\Gamma_{j}=50 \mathrm{~cm}^{-1} \\
\omega_{\mathrm{t}}=328.5 \mathrm{~cm}^{-1} \\
\omega_{\mathrm{L}}=348 \mathrm{~cm}^{-1} \\
\zeta_{j}=398.8 \mathrm{~cm}^{-1} \\
\Gamma_{j}=19 \mathrm{~cm}^{-1} \\
\omega_{\mathrm{t}}=408 \mathrm{~cm}^{-1} \\
\omega_{\mathrm{L}}=521 \mathrm{~cm}^{-1}
\end{array}\right.
\end{aligned}
$$

Kramers-Kronig analysis

$$
\begin{aligned}
& \varepsilon_{\infty}=2.275 \\
& \left\{\begin{array}{r}
\omega_{\max }=314 \mathrm{~cm}^{-1} \\
« \omega_{\mathrm{L}} »=493 \mathrm{~cm}^{-1}
\end{array}\right. \\
& \omega_{\max }=425 \mathrm{~cm}^{-1} \\
& \varepsilon_{\infty}=2.285 \\
& \left\{\begin{array}{r}
\omega_{\max }=170 \mathrm{~cm}^{-1} \\
« \omega_{\mathrm{L}} \rrbracket=232 \mathrm{~cm}^{-1}
\end{array}\right. \\
& \left\{\begin{array}{l}
\text { side } \omega_{\max }=310 \mathrm{~cm}^{-1} \\
\text { band } \omega^{\prime}=250 \mathrm{~cm}^{-1}
\end{array}\right. \\
& \left\{\begin{aligned}
\omega_{\max } & =404 \mathrm{~cm}^{-1} \\
« \omega_{\mathrm{L}} » & =523 \mathrm{~cm}^{-1}
\end{aligned}\right.
\end{aligned}
$$

with

$$
\sqrt{\varepsilon(\omega)}=n+i k=\frac{1+\sqrt{R} \mathrm{e}^{i \theta}}{1-\sqrt{R} \mathrm{e}^{i \theta}} .
$$

The reflectivity was extrapolated to zero frequency by taking a constant value in this region as suggested by the experimental results (see Figs. 1, 2). Between 5000 and $30000 \mathrm{~cm}^{-1}$ we extrapolated the reflectivity by using the values calculated from classical oscillator dispersion, however the strength of the high frequency oscillator is fitted to the experimental value of the reflectivity at $5000 \mathrm{~cm}^{-1}$. From $30000 \mathrm{~cm}^{-1}$ to infinity we calculated the contribution to the value of $\theta(\omega)$ by taking $R\left(\omega^{\prime}\right)$ equal to the value of $R(30000)$.

We report the value obtained by K.K. analysis for $\overline{\bar{\varepsilon}}^{\prime \prime}(\omega)$ in figures 3,4 for the both polarizations.

We also report the value of $\overline{\bar{\varepsilon}}^{\prime \prime}(\omega)$ obtained from the classical oscillators analysis.

For the polarization parallel to the $\mathbf{c}$ axis both analyses give nearly identical results, in particular we find the weak side band in the $430 \mathrm{~cm}^{-1}$ region (note that a weak supplementary oscillator has been introduced in the oscillator dispersion analysis).

However for the polarization perpendicular to the c axis the two analyses give very different results :

- in the $200-270 \mathrm{~cm}^{-1}$ region we obtain two peaks at 250 and $310 \mathrm{~cm}^{-1}$;

- the band at $420 \mathrm{~cm}^{-1}$ looks quite different. We report in table I the values of the transverse 


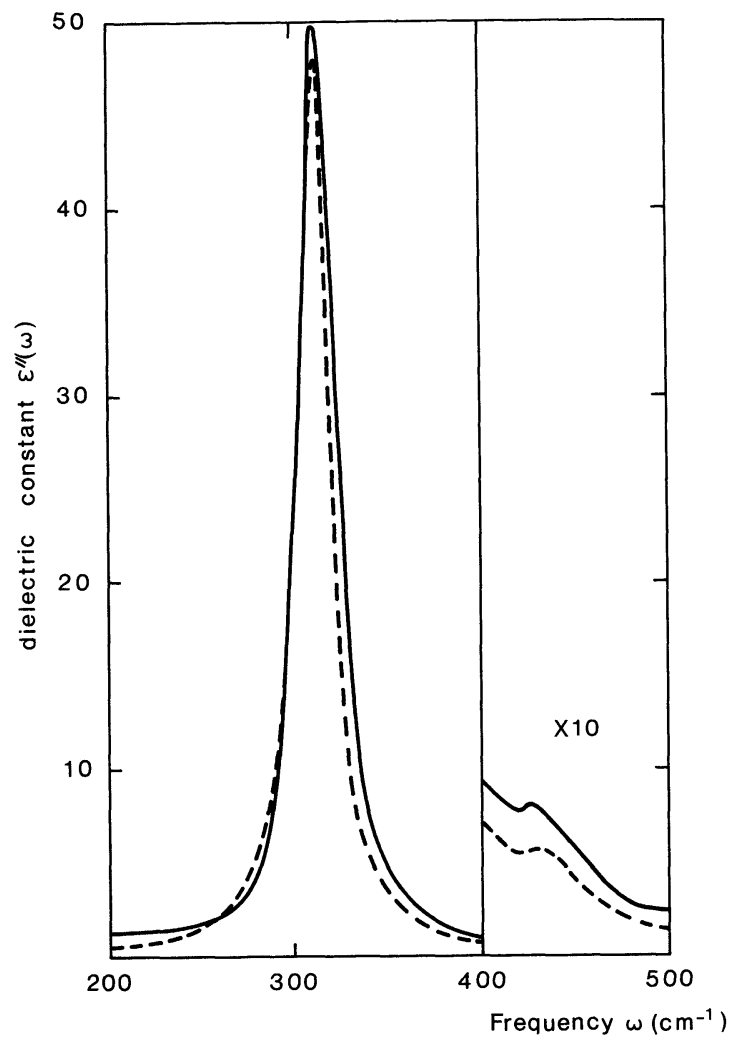

Fig. 3. - Imaginary part of the dielectric constant for a polarization parallel to the axis. Full line results from a Kramers-Kronig analysis, dashed line is calculated by an oscillator model.

mode frequencies (taken at the peaks of $\bar{\varepsilon}^{\prime \prime}(\omega)$ ) and of the longitudinal mode frequencies (taken at some of the zeros of the $\overline{\bar{\varepsilon}}^{\prime}(\omega)$ function).

If we take into account the anharmonicity of the crystal the response to an electromagnetic field can be written as [6]

with

$$
\overline{\bar{\varepsilon}}(\omega)=\overline{\bar{\varepsilon}}(\infty)+4 \pi \overline{\bar{\chi}}(\omega)
$$

$$
\chi_{\alpha \beta}(\omega)=\sum_{j} \tilde{M}_{\alpha j} \tilde{M}_{\beta j} G_{j}(\omega)
$$

$\tilde{M}_{\alpha j}$ is the renormalized linear dipole moment and

$$
G_{j}(\omega)=\frac{2 \omega_{j}}{\omega_{j}^{2}-\omega^{2}-2 \omega_{j}\left[\Pi_{j}(\omega)-\Pi_{j j^{\prime}}^{2} G_{j^{\prime}}(\omega)\right]}
$$

where

$$
\Pi_{j}(\omega)=\Delta_{j}(\omega)-i \Gamma_{j}(\omega)
$$

is the self energy of the phonon $j$ and

$$
\Pi_{j j^{\prime}}^{2}(\omega)=\Delta_{j j^{\prime}}(\omega)-i \Gamma_{j j^{\prime}}(\omega)
$$

is a term which defines the coupling between the modes $j$ and $j^{\prime}$. If the coupling between oscillators is not too strong we can neglect the $\Pi_{j j^{\prime}}^{2}$ terms.

In very anaharmonic crystals or in a crystal with a density of modes having a very high value in some

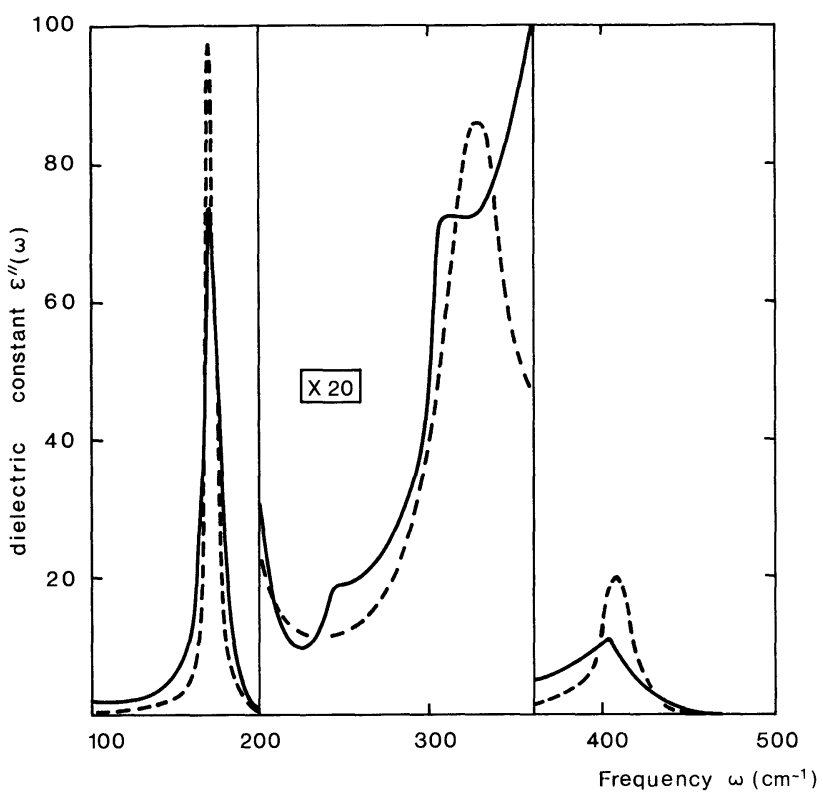

Fig. 4. - Imaginary part of the dielectric constant for a polarization perpendicular to the axis : the definitions of full and dashed lines are as in figure 3.

region the imaginary part of the self energy function may present strong maxima and the function $\overline{\bar{\varepsilon}}^{\prime \prime}(\omega)$ can present supplementary peaks. For instance, the band at $430 \mathrm{~cm}^{-1}$ in the spectrum for polarization parallel to the $c$ axis is certainly due to a maximum in the $\Gamma_{j}(\omega)$ imaginary part of the self energy of the $A_{2 u}$ phonon.

Such a side band appears in the infrared spectrum of $\mathrm{MgF}_{2}$ at $556 \mathrm{~cm}^{-1}$ [5], [8]. In this last case using the calculated phonon dispersion curves [9] together with the appropriate selection rules for two-phonon processes at the $\Gamma(\mathbf{q}=000), X\left(\mathbf{q}=\frac{1}{2} 00\right), \mathbf{M}\left(\mathbf{q}=\frac{1}{2} \frac{1}{2} 0\right)$ and $Z\left(q=00 \frac{1}{2}\right)$ points, one finds only two allowed combinations for the interpretation of the side band frequency and for a polarization parallel to the axis. These are two $X_{1} \otimes X_{2}$ combinations :

$X_{1}$ at $137 \mathrm{~cm}^{-1}$ combined with $X_{2}$ at $413 \mathrm{~cm}^{-1}$ and

$X_{1}$ at $267 \mathrm{~cm}^{-1}$ combined with $X_{2}$ at $296 \mathrm{~cm}^{-1}$.

The sum of frequencies are $550 \mathrm{~cm}^{-1}$ and $563 \mathrm{~cm}^{-1}$, respectively. As the two modes implicated in the first process correspond precisely to very strong peaks in the one phonon density of states we believe that this combination is responsible alone for the observed side band intensity.

Applying the same arguments in the case of $\mathrm{FeF}_{2}$ the corresponding combined modes are [10] :

$$
X_{1} \text { at } 110 \mathrm{~cm}^{-1} \text { combined with } X_{2} \text { at } 319 \mathrm{~cm}^{-1}
$$
and

$X_{1}$ at $222 \mathrm{~cm}^{-1}$ combined with $X_{2}$ at $255 \mathrm{~cm}^{-1}$

which give for the frequency sum $429 \mathrm{~cm}^{-1}$ and $477 \mathrm{~cm}^{-1}$, respectively. As the side band frequency 
is $437 \mathrm{~cm}^{-1}$ in this case one obtains here a confirmation of the previous interpretation.

The spectrum for polarization perpendicular to the $c$ axis may be explained in the same way by the self energy of $\mathrm{E}_{\mathrm{u} 2}$ mode. We think that the $\mathrm{E}_{\mathrm{u} 2}$ mode frequency is close to $310 \mathrm{~cm}^{-1}$. The complex line width, $\Gamma_{\mathrm{E}_{\mathrm{u} 2}}(\omega)$, of this mode changes the shape of the
$\mathrm{E}_{\mathrm{u} 3}$ mode spectrum and produces a side, band at $250 \mathrm{~cm}^{-1}$.

The interpretation of this side band is not clear at present and a systematic study of the temperature effects on the infrared spectrum seems to be desirable in order to clarify the origin of the side band. This study is presently being carried out.

\section{References}

[1] Rainford, B. D., Houmann, J. C., Guogenheim, H. J., I.A.E.A. Grenoble P. 655 (1972).

[2] Sauvajol, J. L., Almairac, R., Benoit, C., Bon, A. M., Lattice dynamics (Flammarion, Paris) 1977, p. 199.

[3] Balkanski, M., Мoch, P., Parisot, G., J. Chem. Phys. 44 (1966) 940.

[4] Cadene, M., Benoit, C., Revue Phys. Appl. 7 (1972) 395.

[5] Barker, A. S., Phys. Rev. 136 (1964) 1290.

[6] $\mathrm{BLZ}, \mathrm{H}$., in Phonons in perfect lattices and in lattices with point imperfection, Eds. Stevenson, Olivier and Boyd (1966), p. 208.
[7] Krauzman, M., Pick, R. M., Poulet, H., Hamel, G. and Prevot, B., Phys. Rev. Lett. 33 (1974) 528.

[8] Benort, C., J. Physique 31 (1970) 1005.

[9] Almairac, R., Sauvajol, J. L., Benotr, C. and Bon, A. M., J. Phys. C. Solid State Phys. 11 (1978) 3157.

[10] To be published.

[11] JACOBSEN, C. S., TANNER, D. B., Garito, A. F. and HeEGER, A. J., Phys. Rev. Lett. 33 (1974) 1559. 